\title{
Enhanced peer-review for optimising publication of biomedical papers submitted from low- and middle-income countries: feasibility study for a randomised controlled trial - CORRIGENDUM
}

Alexandra Pitman, Raphael Underwood, Adam Hamilton, Peter Tyrer and Min Yang

\section{Keywords}

Low and middle income countries; randomized controlled trial; feasibility study; peer review; capacity building; erratum.

\section{Copyright and usage}

(c) The Royal College of Psychiatrists 2019. This is an Open Access article, distributed under the terms of the creative Commons Attribution licence (http://creativecommons.org/licenses/by/4.0/), which permits unrestricted re-use, distribution, and reproduction in any medium, provided the original work is properly cited.

https://doi.org/10.1192/bjo.2018.89, Published online by Cambridge University Press, 04 February 2019

In the original publication of this article the article title and number were incorrectly stated.

The correct citation details are as follows:
Pitman A, Underwood R, Hamilton A, Tyrer P, Yang M. Enhanced peer-review for optimising publication of biomedical papers submitted from low- and middle-income countries: feasibility study for a randomised controlled trial. BJPsych Open 2019; 5(2): e20. https://doi.org/10.1192/bjo.2018.89.

This has now been updated in the original article online.

The publisher and author sincerely apologise for these errors.

\section{Reference}

Pitman A, Underwood R, Hamilton A, Tyrer P, Yang M. Enhanced peer-review for optimising publication of biomedical papers submitted from low- and middleincome countries: feasibility study for a randomised controlled trial. BJPsych Open 2019; 5(2): e20. https://doi.org/10.1192/bjo.2018.89. 